\title{
ALTERAÇÕES CLIMÁTICAS, RISCOS E ESTRATÉGIAS DE ADAPTAÇÃO NO CONTEXTO BRASILEIRO
}

\author{
Luciana Stephani Silva Iocca \\ Doutoranda em Território, Risco e Políticas Públicas pela Universidade de Aveiro (UA), \\ Portugal. Doutoranda em Direito, em regime de cotutela, pela Universidade Federal de Santa \\ Catarina (UFSC). Mestre em Política Social pela Universidade Federal de Mato Grosso \\ (UFMT). Bacharel em Direito pela Pontifícia Universidade Católica de São Paulo (PUC-SP). \\ Investigadora integrada ao Instituto de Direito, Pesquisa \\ e Movimentos Sociais (IPDMS). Advogada. \\ Email: lucianaiocca@hotmail.com \\ Teresa Fidélis \\ Doutora em Ciências Aplicadas ao Ambiente pela Universidade de Aveiro, Aveiro, Portugal. \\ Mestre em Planeamento Regional e Urbano pela Universidade de Manchester, Reino Unido \\ e Licenciada em Planeamento Regional e Urbano pela Universidade de Aveiro, Portugal. \\ Professora Auxiliar no Departamento de Ambiente e Ordenamento da Universidade de Aveiro, \\ Portugal. Investigadora integrada no Centro de Governação, \\ Competitividade e Politicas Publicas (GOVCOPP). \\ Email: teresafidelis@ua.pt
}

\section{RESUMO}

A qualidade ambiental e a adaptação aos riscos das alterações climáticas têm vindo a mobilizar a atenção da comunidade acadêmica e dos decisores um pouco por todo o mundo. $\mathrm{O}$ uso do território e dos seus recursos ambientais, em níveis capazes de garantir a regeneração e resiliência das populações e dos ecossistemas, bem como a estruturação de uma governança ambiental a nível internacional e nacional, capaz de equacionar as vulnerabilidades ambientais sob diversos prismas, têm vindo a configurar-se como um desafio a partilhar por vários países. A partilha deste desafio traduz-se em diversos instrumentos jurídicos internacionais como a Convenção-Quadro das Nações Unidas sobre Mudança do Clima. Este artigo tem por objetivo analisar o modo como as Convenções sobre Mudança do Clima têm vindo a ser internalizadas no Brasil e em que medida a política de adaptação às alterações climáticas se traduz em instrumentos legislativos relacionados com a prevenção de riscos climáticos.O estudo, baseado numa análise documental qualitativa, permite evidenciar que o Brasil construiu um 
edifício legislativo robusto, tendo em vista a gestão dos recursos naturais e a gestão dos riscos. Contudo, a ausência de ferramentas de avaliação de sua efetiva implementação pode constituir objeto de preocupação.

Palavras-Chave: alterações climáticas; governança ambiental; convenções internacionais; políticas públicas; Brasil

\title{
CLIMATE CHANGE, RISK AND STRATEGIES FOR ADAPTATION IN THE BRAZILIAN CONTEXT
}

\begin{abstract}
Environmental quality and adaptation to climate change risks is mobilizing the attention of the academic community and policymakers around the world. The use of the territory and its environmental resources at levels capable of ensuring the regeneration and resilience of populations and ecosystems, as well as the structuring of international and national environmental governance capable of equating environmental vulnerabilities under different prisms, has become a challenge to be shared by many countries. The sharing this challenge is reflected in a number of international legal instruments such as the United Nations Framework Convention on Climate Change. The purpose of this article is to analyze how the Climate Change Conventions have been internalized in Brazil and to what extent climate change adaptation policy is translated into legislative instruments related to the prevention of climatic risks. The study, based on a qualitative document analysis, shows that Brazil has built a robust legislative framework for the management of natural resources and risk management. However, the lack of tools to evaluate its effective implementation can be a matter of concern.
\end{abstract}

Key-words:climate change, environmental governance, international conventions, public policies, Brasil 


\section{INTRODUÇÃO}

Aquestão ambiental é objeto de importantes estudos, evidenciando uma preocupação da comunidade científica sobre o modo como a relação entre o ser humano e o ambiente vem sendo concretizada. Neste contexto, tem vindo a defender-se que essa relação se enquadre no paradigma da sustentabilidade e da adaptação às alterações climáticas, garantindo o uso do território e dos seus recursos ambientais em níveis capazes de garantir a regeneração e resiliência das populações e dos ecossistemas, bem como a estruturação de uma governança ambiental a nível internacional e nacional, capaz de equacionar as vulnerabilidades ambientais sob diversos prismas, configurando-se, assim, como um desafio partilhado por vários países.

A crescente preocupação com as questões ambientais resultou em vários acordos de âmbito internacional. Um levantamento no site do Programa das Nações Unidas para o Meio Ambiente permite identificar a existência de mais de 280 acordos multilaterais sobre a questão ambiental, figurando como uma das temáticas mais tratadas em âmbito internacional. Entre esses acordos, assumem especial relevância as convenções resultantes da Conferência das Nações Unidas sobre Meio Ambiente e Desenvolvimento, ocorrida em 1992, na cidade do Rio de Janeiro. Esta conferência foi entendida como um marco na estruturação de uma governança ambiental a nível internacional, tendo dado origem a várias convenções, dentre elas, a Convenção-Quadro das Nações Unidas sobre Alterações Climáticas (UNFCCC).

A UNFCCC (sigla em inglês), figura como um dos primeiros instrumentos internacionais criado para enfrentar os potenciais riscos e impactos gerados pelas alterações climáticas e resultou do reconhecimento, pelos países signatários, da necessidade de trabalharem em conjunto nesta matéria. A UNFCCC entrou em vigor em 1994, com 196 paísesmembros, tendo definido o papel de cada país no controle do aquecimento global. Trata-se de instrumento juridicamente vinculativo, ou seja, os países assumem o compromisso de concretizar os objetivos e medidas da convenção, de estabilizar as concentrações de gases que contribuem para o efeito estufa, de criar planos nacionais para adaptação às alterações climáticas e de promover a transferência de tecnologia relevante para este efeito. Os países assumem, ainda, o compromisso de se reunirem anualmente nas chamadas Conferências dos Membros, conhecidas como COP (UNFCCC, 2018). 
No âmbito da UNFCCC, foi assinado em 1997 o Protocolo de Quioto, o qual estabeleceu metas para redução dos gases que contribuem para o efeito estufa, associado às alterações climáticas, mas que só em 2005 alcançou o número mínimo de países signatários para entrar em vigor. O protocolo foi ratificado por 192 países, definia compromissos ambientais para 37 países industrializados, considerados os maiores responsáveis pela poluição atmosférica nos últimos 150 anos, estando estes obrigados a diminuir em 5\% o volume de emissão de gases (UNFCCC, 2018). Contudo, além de não prever penalizações ao seu descumprimento, o protocolo não contou com a adesão dos países considerados os maiores poluidores, limitando, assim, o alcance dos objetivos propostos.

$\mathrm{Na}$ tentativa de flexibilizar as metas do Protocolo de Quioto, ampliando a adesão de países às metas de redução de emissão de gases, foi criada, em 2009, a Declaração de Compenhague, mas que não alcançou o necessário consenso entre os Estados, havendo baixa adesão. Em 2010, a Declaração de Cancún é adotada, sem efeito vinculativo, detalhando e expandindo os objetivos da Declaração de Compenhague. Com o fim do período de vigência do Protocolo de Quioto, é criada, em 2012, a Emenda de Doha, a qual propõe um segundo período de compromisso, compreendido de 2013 a 2020, no qual os países participantes se comprometem a reduzir as emissões de gazes poluentes em, pelo menos, $18 \%$ em relação aos níveis de 1990 (UNFCCC, 2018). Entretanto, com o início das negociações para um novo acordo climático, sua adesão foi desestimulada, motivo pelo qual esta ainda não entrou em vigor, contando com 84 ratificações até a presente data (UNFCCC, 2018).

Em 2015, foi firmado o Acordo de Paris, sucessor ao Protocolo de Quioto. O Acordo abrange todos os países da UNFCCC e incentiva ações voluntárias, pautando-se no princípio da transparência. $\mathrm{O}$ seu foco não está no caráter punitivo, mas sim na ampliação da consciência ecológica das Nações e no compromisso de cada uma frente à continuidade da vida digna no planeta. O Acordo de Paris entrou em vigor em 2016, com 169 ratificações, tendo a sua data de implementação prevista para 2020, ano em que se encerra a vigência da Emenda de Doha.O Acordo de Paris propõe um plano de ação destinado a limitar o aquecimento global a um valor abaixo dos $2{ }^{\circ} \mathrm{C}$. Os países participantes acordaram em comunicar, a cada cinco anos, seus contributos para estabelecer metas mais ambiciosas para mitigação e adaptação aos impactos das alterações climáticas. As metas deste acordo pautam-se, ainda, na transparência e solidariedade entre os 
países, motivo pelo qual estes aceitaram apresentar relatórios aos demais governos e à sociedade civil sobre seu desempenho no cumprimento das metas e os países em desenvolvimentos continuarão a receber financiamentos para reduzir a emissão de gazes, garantir a implementação de seus planos estratégicos, ampliando sua resiliência frente aos impactos das alterações climáticas (UNFCCC, 2018).

O protagonismo do Brasil no contexto da Eco-92 é mundialmente reconhecido, sendo um dos primeiros a assinar as convenções criadas no âmbito da conferência, dentre elas a Convenção-Quadro das Nações Unidas sobre Mudança do Clima. O presente estudo centra-se, assim, no quadro jurídico brasileiro e tem por finalidade analisar de que modo os objetivos assumidos com a assinatura das convenções sobre alterações climáticas, acima referidas, se traduziram em documentos legislativos e de política pública e quais os principais contornos das estratégias de adaptação às alterações climáticas adotadas. O artigo divide-se em três seções. Depois desta introdução, na seção 1, apresenta-se uma breve contextualização dos desafios de integração de novas normativas relacionadas com os riscos e as alterações climáticas, nos mecanismos de governança ambiental para a adaptação, prevenção ou minimização. Na seção 2 , descreve-se a metodologia adotada para analisar um conjunto de documentos de política pública previamente selecionados. Na seção 3 , expõe-se o enquadramento legislativo sobre alterações climáticas no Brasil, identificam-se os documentos que estabelecem os contornos da política pública nesta matéria, analisando-os de acordo com a metodologia referida na secção 2. Mais tarde, discutem-se os resultados à luz da contextualização teórica exposta na secção1. Por fim, apresentam-se as principais conclusões e recomendações.

\section{RISCOS, ALTERAÇÕES CLIMÁTICAS E INTERNALIZAÇÃO NA GOVERNANÇAAMBIENTAL}

O modelo conceitual de risco pode ser expresso pela relação probabilidade $\mathrm{x}$ consequência (COROMINAS, et al., 2015), por meio da qual se tem a probabilidade de ocorrência de um evento e suas consequências negativas. Aragão (2008) considera a existência de riscos planetários, uma vez que "as ações conjugadas da evolução científica e tecnológica e da intensificação da produção agrícola, com a aceleração do consumo e a globalização do mercado dos produtos e serviços, conduzem 
a uma massificação dos riscos" (ARAGÃO, 2008, p. 21). Segundo Mendes (2015), o conceito de risco remonta aos acidentes de trabalho do século XIX e, a partir do século XX, a um fenômeno característico das mudanças sociais que fundam um novo tipo de modernidade (MENDES, 2015). Ao analisar as diferentes perspectivas sociológicas e culturais do risco, este autor evidencia o risco como produto da organização social, sublinhando, assim, o argumento de Aragão (2008, p.21).

O termo sociedade de risco, muito debatido a partir da teoria de Beck (2011), se refere ao perigo associado ao processo de tomada de decisão, considerando que o processo produtivo e os avanços tecnológicos possuem origem antrópica. Não obstante, considera que a distribuição do risco está diretamente relacionada com as desigualdades sociais, levando a uma distribuição injusta das consequências dos eventos danosos.Os riscos são encarados como resultado da modernidade tardia, em que "a produção social de riqueza é acompanhada sistematicamente pela produção social de riscos" (BECK, 2011, p. 23).

Dentro do contexto das alterações climáticas, a prevenção e gestão dos riscos (AYALA-CARCEDO, 2002) vem sublinhando a importância da gestão do território (TAVARES, 2013), ao se reconhecer que a relação predatória e a exploração dos recursos naturais disponíveis têm gerado não apenas graves danos ambientais, mas também riscos pouco conhecidos, ou, imensuráveis (BECK, 2011), constituindo uma ameaça às gerações presentes e futuras (ARAGÃO, 2008).

A formulação de planos estratégicos para gestão de riscos depende diretamente de estudos capazes de identificar e mensurar os riscos, a partir de seus diferentes níveis e fatores, propondo medidas para evitar ou minimizar seus impactos (AYALA-CARCEDO, 2002). Tavares (2013), ao analisar diferentes modelos de gestão de riscos, evidencia o modelo do International Risk Governance Council (Figura 1), o qual "privilegia a comunicação e o envolvimento dos diferentes atores. Trata-se de um modelo cíclico que engloba desde processos de aquisição de conhecimento a processos de decisão, baseados na comunicação permanente entre cidadãos, técnicos e decisores" (TAVARES, 2013, p. 70). 


\section{Figura 1 - Modelo de gestão do risco}

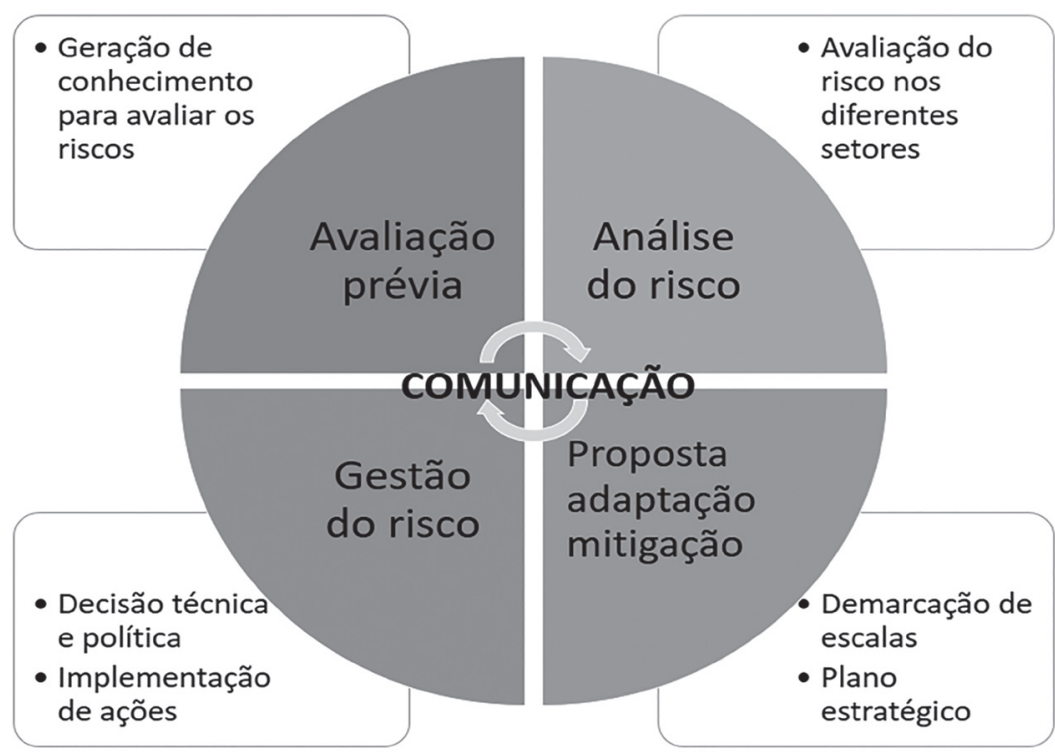

Fonte: Adptado de Tavares (2013, p. 70)

Aamplitude dos potenciais riscos das alterações climáticas faz com que se constituam como uma preocupação global. Os cenários projetados pela comunidade científica, em diferentes países e escalas (CHOU et al., 2014; IPCC, 2014; UFSC, 2016), desafiam a formulação de estratégias de gestão dos riscos (AYALA-CARCEDO, 2002; (HILL; DINSDALE, 2003; CUNHA et al., 2011; TAVARES, 2013), as quais perpassam pelos diversos níveis de governança, evidenciando a importância da demarcação e articulação das escalas (desde supranacionais a locais) para a efetividade da gestão dos riscos (CUNHA et al., 2011;TAVARES, 2013), permitindo a definição de estratégias capazes de atender aos diferentes contextos.

Ao refletir sobre o papel dos planos estratégicos em matéria ambiental e de ordenamento do território, Partidário (2012) salienta que estes são criados para superar barreiras, definir métodos, técnicas e ações a curto, médio e longo prazo. No contexto público, os planos não servem para dizer como o futuro deve ser, mas sim, para viabilizar sua chegada a ele, a partir da capacidade estratégica de olhar para o futuro, dentro de 1 Adaptado por Tavares (2013) a partir de IRGC (2005). 
um contexto multiescalar e multivalor, refletindo a proposta de sociedade para o futuro e seu modo de concretizá-lo (PARTIDÁRIO, 2012). Neste contexto, os tratados internacionais revestem-se de especial importância, sendo relevante estudar não apenas o processo de relações internacionais que permitem a adopção de novas estratégias para gestão dos riscos provenientes das alterações climáticas, mas, também, o modo como os países signatários desenvolvem esforços para a sua prossecução.

$\mathrm{O}$ direito internacional constitui um sistema legal próprio (HENKIN, 1999) e, entre diversos instrumentos usados, conforme dispõe o artigo 38, alínea 'a', do Estatuto do Tribunal Internacional de Justiça, estão os tratados internacionais. Os tratados são a expressão da plataforma de consenso obtida entre os países envolvidos, mas a sua internalização e implementação dependem da sua confirmação formal pelos Estados signatários, o que se dá por meio da ratificação, ato pelo qual o tratado passa a ter efeito vinculativo (RESEK, 2012). Ao serem internalizados, os tratados assumem importante papel, por possuírem poder normativo e pela capacidade de influenciarem as demais normas e políticas em âmbito regional e nacional, principalmente no que tange às temáticas relacionadas aos direitos humanos (MAZZUOLI eTEIXEIRA, 2013).

O grande número de tratados em torno das temáticas ambientais não expressa apenas a compreensão pela importância da gestão dos recursos ambientais e da consciência ecológica, mas, reflecte também o crescente reconhecimento das nações sobre as implicações dos problemas ambientais nos diversos setores econômicos, bem como na sociedade em geral. Adicionalmente, identifica-se um crescente reconhecimento dos direitos ambientais como uma das dimensões dos direitos humanos, fortalecendo e ampliando as discussões sobre a temática no plano internacional (FRÖHLICH e KNIELING, 2013). Neste contexto, as mudanças climáticas têm sido apontadas como a questão ambiental de maior impacto no modo de vida da sociedade (IPCC, 2014), exigindo uma postura proativa dos diferentes Estados face a esta problemática, visando contribuir, entre outros aspectos, para a formulação e adoção de tratados que permitam a construção de agendas políticas que compreendam a mitigação e a adaptação às alterações climáticas, a partir de uma abordagem transfronteiriça e multinível, como um desafio multissetorial e multiator, com as características específicas da longevidade (FRÖHLICH e KNIELING, 2013). Nesta conjuntura, evidencia-se a necessária coerência que deve haver na construção da estrutura legislativa e dos instrumentos 
institucionais que visam concretizar os tratados internacionais, garantindo a gestão eficaz dos riscos.

\begin{abstract}
A gestão eficaz de riscos é crucial para o serviço público; a capacidade de tomar decisões corretas em relação a políticas, programas e serviços, em ambiente caracterizado por incertezas, é fundamental. Cada vez mais, o serviço público tem sido forçado a tomar decisões difíceis sobre riscos de saúde, riscos ambientais, riscos de bem-estar econômico, riscos tecnológicos e riscos envolvidos na prestação de serviços, entre vários outros. As responsabilidades e deveres do governo em relação ao bem público exigem a adoção de práticas e estratégias eficazes de gestão de risco (HILL; DINSDALE, 2003, p. 9).
\end{abstract}

A gestão eficaz do risco dá-se dentro do processo de governança, o qual engloba a avaliação, gestão e comunicação de riscos, conforme evidenciado na Figura 1. O termo governança passou a ser utilizado a partir dos trabalhos desenvolvidos pelo Banco Mundial, visando aprofundar os conhecimentos em relação às condições capazes de garantir um Estado eficiente, englobando os desafios e responsabilidades que a sociedade moderna coloca sobre o ato de governar (DINIZ, 1995; WOLKMER e FREIBERGER, 2013). A Comissão sobre Governança Global das Nações Unidas define governança como:

\begin{abstract}
A soma total dos vários modos como indivíduos e instituições, públicos e privados, administram seus negócios comuns. Trata-se de um processo contínuo, por meio do qual, interesses conflitantes ou diversos podem ser acomodados e uma ação cooperativa estabelecida. Esse processo inclui instituições e regimes formais investidos de poder para impor a observância das regras, do mesmo modo que arranjos informais que pessoas e instituições concordaram em estabelecer ou percebem ser de seu interesse (Commission on Global Governance, 1995, p. 53).
\end{abstract}

$\mathrm{Na}$ governança, o Estado assume, ainda, o papel de gestor estratégico, num processo que envolve articulação e cooperação entre atores sociais e políticos, nos diversos arranjos institucionais, no planejamento, formulação e implementação das políticas, com base nos princípios de responsabilização, fortalecimento institucional e de gestão (KNIELING e LEAL FILHO, 2013). A participação dos diferentes segmentos da sociedade civil (stakeholders), por sua vez, é ponto fundamental da boa governança, em especial nas questões ambientais, pois 
tem a capacidade de fortalecer o espaço público na estruturação das novas políticas públicas, "conformando práticas inovadoras que rompem com a dinâmica anterior de gestão ambiental" (WOLKMER, et. al., 2014, p. 375). Agovernança ambiental envolve um conjunto de políticas, programas e acordos internacionais, construindo um sistema de gestão ambiental que, necessariamente, pressupõe a criação de mecanismos que garantam a participação democrática da sociedade civil (PORTO e PORTO, 2015), tendo a capacidade de melhorar a qualidade das decisões e reforçar a confiança nas instituições públicas.

Segundo Bursztyn e Bursztyn (2012,p. 187), é possível identificar três gerações de políticas públicas voltadas à proteção ambiental, em diferentes países, dentre os quais inclui-se o Brasil. Na primeira geração, "os aparelhos de Estado voltavam a sua atenção para a normatização do uso dos recursos ambientais, outorgando a instituições de ação setorial a autoridade da aplicação de códigos específicos". A segunda geração, que se estendeu do início da década de 70 até ao final do século XX, caracterizouse pela tomada de consciência social a respeito do ambiente e da relação entre o ser humano e a natureza, originou políticas "sem grandes vínculos com as outras políticas públicas setoriais" e a criação de novos organismos públicos com funções específicas (secretarias ou ministérios). A terceira geração, "que ainda se delineia" (e que não elimina as anteriores), é marcada pela emergência de novos atores no cenário da governança ambiental, tanto ao nível internacional, como a nível dos agentes produtivos e movimentos sociais.

Ao refletir sobre a governança no contexto europeu, Aragão (2008) identifica que ela estrutura-se em torno de um conjunto de princípios, a saber: transparência, abertura, participação, responsabilização, eficácia e coerência (ARAGÃO, 2008,p. 37), salientando que, com base nos princípios da transparência e da abertura, "a participação deve ser informada, precoce, alargada, plural e útil", tratando-se de "dimensão recente da governância dos riscos: a relevância atribuída aos cidadãos, leigos cuja opinião profana foi, desde sempre, desprezada e só recentemente, com a Convenção de Aarhus, começou a ganhar algum estatuto.” (ARAGÃO, 2008, p. 43) ${ }^{2}$. Diante deste contexto, os diferentes atores passam a assumir maior interação e atuação, reforça-se a necessidade de conciliação de interesses

2 Sobre a opção linguística da autora entre "governança" e "governância", ver seu artigo sobre "A Governância na ConstituiçãoEuropeia. Uma oportunidade perdida?», in: A Constituição Europeia. Estudos em homenagem ao Prof. DoutorLucas Pires, FDUC, Coimbra, 2005. 
e constroem-se cenários de correlação de forças com implicações diretas sobre os processos de formulação e implementação de políticas públicas.

Ao refletir específicamente sobre a governança das mudanças climáticas, Fröhlich e Knieling (2013) argumentam que as soluções no campo da mitigação e adaptação às mudanças climáticas dificilmente serão bem-sucedidas sem uma compreensão da estrutura do problema, exigindo, portanto, ações colaborativas das partes interessadas e decisores políticos que moldam a mitigação e adaptação, evitando a construção de modelos baseados em respostas de cima para baixo (AYALA-CARCEDO, 2002).

\section{METODOLOGIA}

O presente artigo centra-se na análise qualitativa de documentos e tem por objetivo identificar e analisar como as Convenções sobre Mudança do Clima vêm sendo internalizadas no contexto legislativo brasileiro e em que medida as políticas decorrentes deste edifício legislativo se traduzem em instrumentos de gestão de riscos.O estudo desenvolve-se nas seguintes etapas:

a primeira etapa centra-se na contextualização das alterações climáticas no Brasil, bem como na descrição dos conceitos-chave, nomeadamente "riscos", "alterações climáticas" e "governança ambiental".

a segunda etapa centra-se na análise dos documentos que consubstanciam a estratégia de adaptação às alterações climáticas adotada no Brasil. Os documentos em estudo incluem a Política Nacional sobre Mudança do Clima (PNMC), instituida pela Lei n ${ }^{\text {. }}$ 12.187, de 29 de dezembro de 2009, o Plano Nacional de Adaptação à Mudança do Clima (PNA) adotado por meio da Portaria n ${ }^{\circ} 150$, em 10 de maio de 2016, formulado na sequência do documento anterior e que visa estabelecer as ações estratégicas, e o Relatório de Monitoramento e Avaliação do PNA, elaborado um ano após a implementação do PNA, de 2016 a 2017.

a terceira etapa centra-se na análise do modo como as medidas estratégicas estabelecidas no PNA, no âmbito da Política Nacional sobre Mudança do Clima, concretizam as Convenções sobre Mudança do Clima e, em especial, se se traduzem na formulação de instrumentos de gestão de riscos climáticos e de identificação das vulnerabilidades do país neste aspecto.

A análise dos documentos teve presente o trabalho de Philips et al. (2004), que desenvolve um modelo de análise de discurso para avaliar o papel de documentos na institucionalização de temas emergentes. Estes 
autores,salientam que as instituições são construídas por meio do discurso e que as narrativas adotadas têm o poder de influenciar a subsequente tomada de decisão.

Salienta-se que a análise dos documentos se deu a partir da identificação dos objetivos propostos, bem como dos riscos identificados e estratégias traçadas no âmbito do Plano Nacional de Adaptação à Mudança do Clima e da verificação da concretização destes objetivos e estratégias no Relatório de Monitoramento e Avaliação do PNA, referentes a um ano de implementação do plano. A partir desta comparação, verificaram-se não só as ações empreendidas, mas também o âmbito de ação, atores participantes e desafios identificados.

\section{ALTERAÇÕES CLIMÁtiCAS E RISCOS AMBIENTAIS NO CONTEXTO BRASILEIRO}

\subsection{Alterações climáticas e políticas públicas}

Os estudos atuais (IPCC, 2014) indicam que os riscos associados às alterações climáticas resultam da interação dos perigos conexos ao clima com a vulnerabilidade e a exposição dos sistemas humanos e naturais. Segundo dados do relatório de danos materiais e prejuízos decorrentes de desastres naturais no Brasil (UFSC, 2016, p. 20-22), os desastres com maior recorrência foram os relativos a estiagens e secas, seguidos por enxurradas, inundações e vendavais, gerando prejuízos em âmbito público e privado, estimados em 15,5 bilhões, somente no período de 2008 a 2011, considerando-se apenas os maiores desastres.

Diante das dimensões continentais do Brasil e da existência de diferentes biomas, verifica-se a incidência das mais variadas tipologias de riscos, ondas de frio e calor, erosão, desertificação, estiagem, inundações, deslizamentos, poluição dos recursos hídricos, os de cunho meteorológico, climatológico e hidrológico, numa conjugação dos riscos naturais e antrópicos, nos quais se incluem os sociais e tecnológicos (UFSC, 2016), demandando uma estrutura de governança capaz de abarcar a extensa e complexa realidade ambiental brasileira. Ao se adotar o desenvolvimento sustentável como um paradigma a ser perseguido pelo conjunto das nações, o Brasil avançou na compreensão de que "a governança se coloca como a ferramenta crítica para que este paradigma se instale como dominante em um determinado contexto social" (MOURA e BEZERRA, 2016, p. 92). 
Segundo as simulações do modelo $\mathrm{ETA}^{3}$ (CHOU et al., 2014), estima-se o aquecimento para todo o continente sul-americano (lado esquerdo da Figura 2), com maior concentração no Centro-Oeste, estendendo-se para as regiões Norte, Nordeste e Sudeste do país até o final do século XXI. Estes máximos de aquecimento médio no final do século podem variar entre $2^{\circ} \mathrm{C}$ a $8^{\circ} \mathrm{C}$ em algumas áreas. $\mathrm{O}$ modelo prevê também a redução das chuvas durante o verão (lado direito da Figura 2), concentrando-se os níveis máximos de redução no Centro-Oeste e Sudeste, expandindo-se para as regiões da Amazônia. Em contrapartida, projeta-se o aumento das chuvas sobre a região Sul.

\section{Figura 2 - Projeções regionalizadas de mudanças na temperatura $\left({ }^{\circ} \mathrm{C}\right)$ e precipitação}

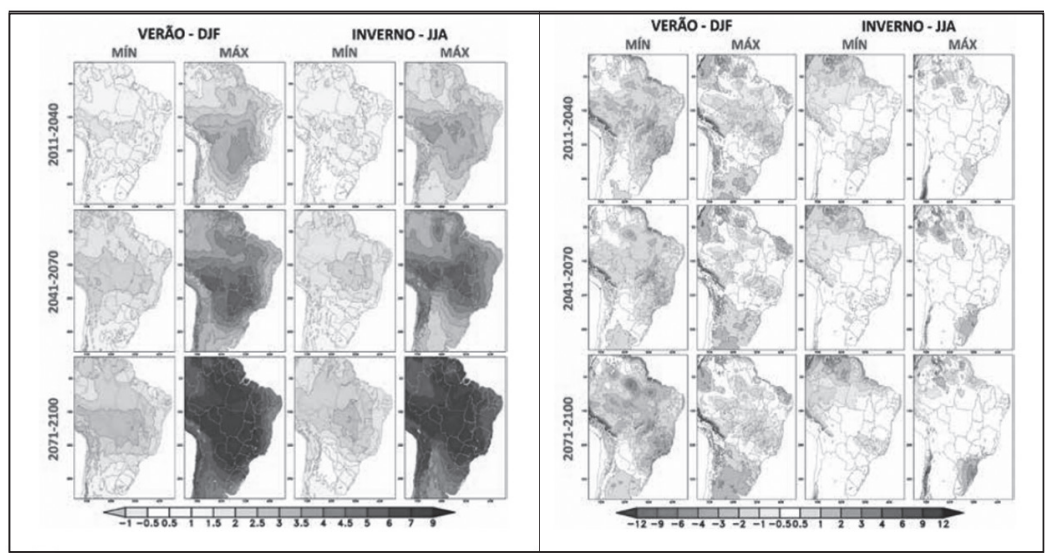

Fonte: Adaptado de CHOU et al., (2014)

As alterações de temperatura e a ocorrência e intensidade das chuvas representam um quadro de projeções climáticas que requerem a gestão dos riscos decorrentes dessas mudanças, identificando as vulnerabilidades territoriais e ambientais, sociais e culturais, bem como as econômicas, advindas deste processo. Neste contexto, a estruturação da

3 "O modelo de área limitada Eta foi desenvolvido pela Universidade de Belgrado, em conjunto com o Instituto de Hidrometeorologia da Iugoslávia, e se tornou operacional no National Centers for Environmental Prediction (NCEP) (Mesinger et al., 1988; Black, 1994). O modelo regional se propõe a prever com maiores detalhes fenômenos associados a frentes, orografia, brisa marítima, tempestades severas etc., enfim, sistemas organizados em mesoscala. Devido a maior não linearidade dos sistemas nesta escala, a previsibilidade é menor e as previsões são de curto prazo." Disponível em: http:// climanalise.cptec.inpe.br/ rclimanl/boletim/cliesp10a/27.html. Acesso em 10/08/18. 
governança ambiental a nível internacional e nacional torna-se um requisito necessário para a salvaguarda do direito ambiental, um direito fundamental de toda humanidade, transfronteiriço, transindividual e intergeracional (ARAGÃO, 2008).

A política ambiental brasileira iniciou sua trajetória em 1934, com a instituição do Código de Águas e do Código Florestal (MOURA, 2016); contudo, foi a partir da Conferência das Nações Unidas sobre Meio Ambiente e Desenvolvimento, em 1992, que o país avançou significativamente na construção do sistema de gestão ambiental nacional, ampliando o arcabouço jurídico e investindo na criação de estrutura institucional tendo em vista a implementação das políticas criadas

No direito brasileiro são conferidos níveis hierárquicos distintos aos tratados e convenções internacionais ratificados, a depender da matéria neles disposta e do processo de incorporação ao ordenamento jurídico. Os tratados que versem sobre direitos humanos e que ingressem no ordenamento jurídico seguindo o procedimento previsto no artigo $5^{\circ}, \S 3^{\circ}$, da Constituição Federal, são equivalentes às emendas constitucionais. Por sua vez, os tratados que não versem sobre direitos humanos ingressam no ordenamento jurídico com força de lei ordinária (MAZZUOLI, 2016).

É relevante salientar que existe divergência em relação aos tratados que versam sobre direitos humanos, mas não foram incorporados ao ordenamento jurídico pelo procedimento previsto no artigo $5^{\circ}, \S 3^{\circ}$ da CF. Neste caso, o entendimento majoritário do Supremo Tribunal Federal tem sido o de conferir força supralegal, ou seja, abaixo da Constituição e acima das leis. Contudo, advogamos em prol do entendimento minoritário, no sentido de reconhecer, aos tratados que versem sobre direitos humanos, a incorporação imediata, após a ratificação, nos termos do artigo $5^{\circ}, \S$ $1^{\circ}$ e $\S 2^{\circ}$ da Constituição Federal, sendo considerados materialmente constitucionais. Assim, compreendendo o direito ambiental como um direito fundamental, tem-se que os tratados firmados no bojo da Eco-92 são materialmente constitucionais.

A Eco-92 representou importante marco no que tange à criação de políticas públicas ambientais no contexto brasileiro, visando combater a desertificação, reduzir os gases que contribuem para o efeito estufa, recuperar as áreas degradadas e preservar os biomas e os recursos hídricos. No que diz respeito especificamente às alterações climáticas, foram criados instrumentos legislativos que visam à implementação da agenda instituída no âmbito da Convenção-Quadro das Nações Unidas sobre Mudança do 
Clima (UNFCCC) e demais convenções sobre o clima

O presente estudo centra-se na Política Nacional sobre Mudança do Clima (PNMC) publicada através da Lei ${ }^{\circ} 12.187 / 2009$ e no plano estratégico dela decorrente (instituído pela Portaria $\mathrm{n}^{\circ} 150$, tendo por objetivo "promover a redução da vulnerabilidade nacional à mudança do clima e realizar uma gestão do risco associada a esse fenômeno"). O estudo também perpassa pela análise do $1^{\circ}$ Relatório de Monitoramento e Avaliação do PNA, após um ano de implementação do Plano (MMA, 2017). A PNMC, regulamentada pelo Decreto $n^{0} 7390 / 2010$, figura desde então como o principal instrumento legislativo nacional de efetivação da Convenção-Quadro das Nações Unidas sobre Mudança do Clima (UNFCCC), criada em 1992. Embora o Brasil seja signatário da UNFCCC desde 1992 e do protocolo de Quioto, desde 2002, só em 2007 foi proposto o projeto de lei que instituiria, em 2009, a Política Nacional sobre Mudança do Clima. O Plano Nacional que estabelece as estratégias de adaptação, por sua vez, foi instituído em 2016.

A análise comparativa da linha temporal associada à Política Nacional sobre Mudança do Clima, com a linha temporal associada à Convenção-Quadro das Nações Unidas sobre Mudança do Clima, representadas na Figura 3, mostra o processo comparado da criação de instrumentos internacionais e a internalização por meio de legislações no contexto brasileiro.

\section{Figura 3 - Linhas temporais associadas às principais políticas de adaptação às alterações climáticas no direito internacional e no direito brasileiro}

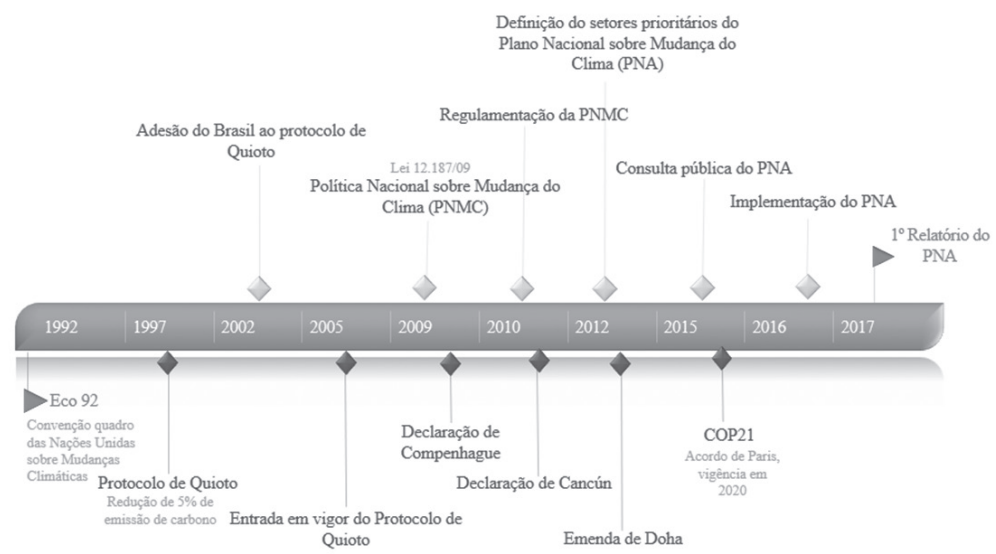

Veredas do Direito, Belo Horizonte, $\cdot$ v.15 $\cdot$ n.33 $\cdot$ p.131-161 $\cdot$ Setembro/Dezembro de 2018 
A Política Nacional sobre Mudança do Clima (PNMC) dispõe sobre a responsabilidade concorrente dos entes políticos e dos órgãos da administração pública na execução da política, observados os princípios da precaução, da prevenção, da participação cidadã, do desenvolvimento sustentável e das responsabilidades comuns (art. $3^{\circ}$ ), estabelecendo, entre as suas diretrizes, os compromissos assumidos pelo Brasil na ConvençãoQuadro das Nações Unidas sobre Mudança do Clima, no Protocolo de Quioto e demais documentos sobre mudança do clima dos quais vier a ser signatário $\left(\operatorname{art.} 5^{\circ}\right)$.

Como compromisso nacional voluntário, a PNMC prevê a redução entre $36,1 \%$ e $38,9 \%$ suas emissões projetadas até 2020 (art. $12^{\circ}$ ). Para efetivação dos objetivos da PMNC, estabelece, entre os instrumentos da política, o Plano Nacional de Adaptação à Mudança do Clima (PNA) (art $6^{\circ}$ ), o qual tem por finalidade instituir medidas de adaptação às mudanças climáticas a partir de setores estratégicos. Neste sentido, oPNA, instituído em 2016, tem por objetivo "promover a redução da vulnerabilidade nacional à mudança do clima e realizar uma gestão do risco associada a esse fenômeno" (BRASIL - PNA, 2016).

A estratégia de adaptação foi pautada no modelo cíclico (HILL e DINSDALE, 2003), o qual envolve a identificação dos riscos atuais e futuros com base em projeções de clima, identificando e analisando as vulnerabilidades para, então, definir as ações e diretrizes de adaptação. O PNA prevê ciclos de execução de quatro anos com suas respectivas revisões, propondo abordagem setorizada, sendo considerados 11 setores, conforme Tabela 1. 


\section{Tabela 1 - Plano Nacional de Adaptação à Mudança do Clima (PNA)}

\begin{tabular}{|c|c|c|}
\hline Setores & Coordenação & Objetivos \\
\hline $\begin{array}{l}\text { Agricultura } \\
\text { Biodiversidade e Ecossistemas } \\
\text { Cidades; } \\
\text { Desastres Naturais; } \\
\text { Indústria e Mineração; } \\
\text { Infraestrutura; } \\
\text { Povos e Comunidades vulneráveis; } \\
\text { Recursos Hídricos; } \\
\text { Saúde; } \\
\text { Segurança Alimentar e Nutricional; } \\
\text { Zonas Costeiras }\end{array}$ & $\begin{array}{l}\text { Grupo Técnico de } \\
\text { Adaptação à Mudança do } \\
\text { Clima-GTA. } \\
\text { O grupo deve funcionar de } \\
\text { forma permanente e possui } \\
\text { caráter consultivo, com } \\
\text { o objetivo de promover a } \\
\text { articulação entre órgãos } \\
\text { e entidades, públicas e } \\
\text { privadas, para promover } \\
\text { a implementação, } \\
\text { monitoramento, avaliação e } \\
\text { revisão do PNA }\end{array}$ & $\begin{array}{l}\text { 1) Orientar a ampliação } \\
\text { e disseminação do } \\
\text { conhecimento científico, } \\
\text { técnico e tradicional } \\
\text { apoiando a produção, } \\
\text { gestão e disseminação } \\
\text { de informação sobre } \\
\text { o risco climático, e o } \\
\text { desenvolvimento de } \\
\text { medidas de capacitação } \\
\text { de entes do governo e da } \\
\text { sociedade em geral; } \\
\text { 2) Promover a } \\
\text { coordenação e cooperação } \\
\text { entre órgãos públicos } \\
\text { para gestão do risco } \\
\text { climático, por meio de } \\
\text { processos participativos } \\
\text { com a sociedade, visando } \\
\text { à melhoria contínua das } \\
\text { ações para a gestão do } \\
\text { risco climático; } \\
\text { 3) Identificar e propor } \\
\text { medidas para promover } \\
\text { a adaptação e a redução } \\
\text { do risco associado à } \\
\text { mudança do clima. }\end{array}$ \\
\hline
\end{tabular}

Entre os onze setores estratégicos adotados, o plano estabelece como prioritárias as áreas de segurança alimentar e nutricional, recursos 
hídricos e energética (esta ultima compreendida no setor de infraestrutura). Segundo as justificações contidas no PNA, a setorização teve em conta primordialmente as divisões de competência no âmbito do Governo Federal e as prioridades e urgências em relação às vulnerabilidades, definidas a partir de projeções de cenário aliadas à política de desenvolvimento adotada pelo país.

O PNA foi subsidiado, entre outros estudos, pelo projeto Vulnerabilidade à Mudança do $\mathrm{Clima}^{4}$, no qual se desenvolveu, em 2014, um software - Sistema de Vulnerabilidade Climática (SisVuClima) - que calcula, em escala municipal, a vulnerabilidade humana às mudanças do clima. O sistema SisVuClima gera índices e mapas temáticos, permitindo aos gestores identificar o grau de vulnerabilidade à mudança climática por município. O projeto contemplou 6 dos 26 estados, quais sejam: Espirito Santo, Pernambuco, Paraná, Maranhão, Amazonas e Mato Grosso do Sul, visando abarcar cada região do país. (BRASIL, 2016).

\subsection{Análise da Política e do Plano Nacional de Mudanças Climáticas}

A análise doPlano de Adaptação (PNA), decorrente da Política Nacional de Mudança do Clima, permite constatar que o Brasil conquistou importantes avanços na estruturação do edifício legislativo em matéria ambiental, traçando metas ambiciosas para a contribuição do Brasil frente às alterações climáticas, estabelecendo no PNA 24 metas e 136 diretrizes, incluindo estratégias transversais e setoriais, que visam à estruturação de bases institucionais, metodológicas e científicas para a redução e gestão do risco associado à mudança do clima.

Segundo informações presentes no primeiro Relatório de Monitoramento e Avaliação do PNA (MMA, 2017), 100\% das metas e 67\% das diretrizes setoriais tiveram alguma ação correspondente implementada. Destas, $72 \%$ contribuem para a identificação e proposição de medidas de adaptação e redução do risco climático, o que se refere ao objetivo número 3 do PNA. Este relatório apresenta as ações implementadas em cada setor estratégico frente aos riscos identificados, acompanhado de um anexo que visa detalhar estas ações (sintetizadas na Tabela 2).

O anexo do relatório (MMA, 2017) enfatiza a situação das ações, o estágio em que se encontram e, em alguns casos, traz comentários $4 \quad$ O Projeto Vulnerabilidade à Mudança do Clima é resultante de uma parceria entre o Ministério do Meio Ambiente e a Fundação Oswaldo Cruz - Fiocruz. O mesmo encontra-se em andamento, podendo ser acessadas mais informações em: http://www.sisvuclima.com.br/ 
visando fornecer esclarecimentos sobre a atuação, considerando as metas e objetivos de cada setor. O relatório enfatiza, também, as limitações encontradas para implementação de ações, os desafios e as próximas ações a serem empreendidas visando superar as dificuldades encontradas no primeiro ano do PNA.

Tabela 2 - Riscos e medidas de adaptação nos setores estratégicos no Plano Nacional de Adaptação à Mudança Climática ( PNA 2016-2017)

\begin{tabular}{|c|c|c|}
\hline Setores & Principais riscos & Estratégias em fase de implementação \\
\hline Agricultura & $\begin{array}{l}\text { Redução da disponibilidade } \\
\text { de água }\end{array}$ & $\begin{array}{l}\text { - Desenvolvimento de Sistema de } \\
\text { Monitoramento Agrometeorológico; } \\
\text { - Ampliação de projetos de pesquisa } \\
\text {-Elaboração de Planos estaduais de } \\
\text { Agricultura de Baixa emissão de } \\
\text { Carbono; }\end{array}$ \\
\hline $\begin{array}{l}\text { Biodiversidade e } \\
\text { Ecossistemas }\end{array}$ & $\begin{array}{l}\text { Eventos extremos ligados } \\
\text { ao aumento da temperatura } \\
\text { e diminuição dos níveis de } \\
\text { precipitação }\end{array}$ & $\begin{array}{l}\text { - Desenvolvimento de estudos para } \\
\text { embasar a elaboração de medidas de } \\
\text { Adaptação baseada em ecossistemas em } \\
\text { áreas de risco. }\end{array}$ \\
\hline Cidades & $\begin{array}{l}\text { Inundações, ondas de calor; } \\
\text { deslizamentos de terra e } \\
\text { limitações no suprimento de } \\
\text { água doce }\end{array}$ & $\begin{array}{l}\text { - Investimento para Urbanização de } \\
\text { Assentamentos Precários } \\
\text { - Continuidade do Programa } \\
\text { Habitacional "Minha Casa, Minha } \\
\text { Vida" } \\
\text { - Obras de Contenção de Encostas em } \\
\text { Áreas Urbanas } \\
\text { - Dez empreendimentos de drenagem } \\
\text { urbana em municípios. }\end{array}$ \\
\hline Desastres Naturais & $\begin{array}{l}\text { Eventos de ocorrência súbita; } \\
\text { eventos de natureza gradativa } \\
\text { (secas e cheias). Pluviosidade } \\
\text { (por excesso ou escassez) }\end{array}$ & $\begin{array}{l}\text { - Estabelecimento de protocolos de } \\
\text { atuação conjunta com órgãos parceiros } \\
\text { no monitoramento e alerta de desastres } \\
\text { naturais } \\
\text { - Curso à distância ( } 30 \mathrm{~h} \text { ) desenvolvido } \\
\text { sobre mudança do clima voltado para } \\
\text { gestores municipais; }\end{array}$ \\
\hline Indústria e Mineração & $\begin{array}{l}\text { Diminuição ou } \\
\text { descontinuidade da atividade } \\
\text { produtiva }\end{array}$ & - Desenvolvimento de estudos \\
\hline
\end{tabular}




\begin{tabular}{|c|c|c|}
\hline $\begin{array}{l}\text { Infraestrutura } \\
\text { (energia, transporte e } \\
\text { mobilidade) }\end{array}$ & $\begin{array}{l}\text { Ocorrência de eventos } \\
\text { extremos; elevação no nível do } \\
\text { mar, interrupções ou reduções } \\
\text { de serviços nos setores de } \\
\text { mobilidade, transporte e } \\
\text { energia. }\end{array}$ & SEM AÇÕES \\
\hline $\begin{array}{l}\text { Povos e Comunidades } \\
\text { vulneráveis }\end{array}$ & $\begin{array}{l}\text { Perda de vidas, perdas } \\
\text { materiais, migrações } \\
\text { forçadas, perda do território, } \\
\text { incapacidade de subsistência } \\
\text { e perda de conhecimentos } \\
\text { tradicionais. }\end{array}$ & $\begin{array}{l}\text { - Eventos (duas reuniões e uma oficina) } \\
\text { de sensibilização sobre mudança do } \\
\text { clima } \\
\text { - Um Curso à distância ( } 30 \mathrm{~h}) \\
\text { desenvolvido sobre mudança do clima } \\
\text { voltado para gestores municipais; }\end{array}$ \\
\hline Recursos Hídricos & $\begin{array}{l}\text { Alterações nos padrões de } \\
\text { temperatura e precipitação } \\
\text { esperadas, impactando na } \\
\text { disponibilidade hídrica } \\
\text { (volumes e distribuição) } \\
\text { e a ocorrência de eventos } \\
\text { extremos ligados à água } \\
\text { (cheias e secas) }\end{array}$ & $\begin{array}{l}\text { - Estudos sobre avaliação de impactos } \\
\text { de estiagem e modelagem dos impactos } \\
\text { da mudança do clima, considerando } \\
\text { os aspectos econômicos, nas bacias } \\
\text { Piracicaba, Capivari e Jundiaí, no estado } \\
\text { de São Paulo, e Piranhas-Açu, que } \\
\text { engloba parte dos estados da Paraíba e } \\
\text { do Rio Grande do Norte } \\
\text { - } 370 \text { sistemas de dessalinização } \\
\text { implantados em municípios do } \\
\text { Nordeste, visando à segurança hídrica } \\
\text { para o abastecimento humano } \\
\text { - Implementação do Monitor de Secas } \\
\text { do Nordeste do Brasil } \\
\text { - Processos de alocação negociada de } \\
\text { água realizados em } 35 \text { sistemas hídricos } \\
\text { isolados } \\
\text { - Realização da "Oficina de Marcos } \\
\text { Regulatórios de Recursos Hídricos no } \\
\text { Semiárido" } \\
\text { - Implementação do Programa Nacional } \\
\text { de monitoramento da Qualidade de } \\
\text { Água }\end{array}$ \\
\hline Saúde & $\begin{array}{l}\text { Alteração no comportamento } \\
\text { das doenças e agravos. } \\
\text { Internações decorrentes de } \\
\text { eventos extremos. }\end{array}$ & $\begin{array}{l}\text { - Aperfeiçoamento da do Sistema de } \\
\text { Informações de Vigilância da Qualidade } \\
\text { da Água para Consumo Humano } \\
\text { • Projeto Educação em Saúde da(o) } \\
\text { Trabalhadora(or) da Pesca Artesanal e } \\
\text { Formação de Agentes Multiplicadoras } \\
\text { em Participação na Gestão do SUS }\end{array}$ \\
\hline
\end{tabular}




\begin{tabular}{|c|c|c|}
\hline $\begin{array}{l}\text { Segurança Alimentar } \\
\text { e Nutricional }\end{array}$ & $\begin{array}{l}\text { Redução na produção de } \\
\text { alimentos e a geração de } \\
\text { trabalho e renda no meio rural }\end{array}$ & $\begin{array}{l}\text { - Implantação de cisternas e outras } \\
\text { tecnologias sociais de acesso à água } \\
\text { para consumo humano } \\
\text { - Implantação de cisternas em escolas } \\
\text { públicas rurais } \\
\text { - Implantação de bancos de sementes } \\
\text { comunitários } \\
\text { - Ampliação de } 70 \text { mil para } 90 \text { mil do } \\
\text { número de famílias beneficiárias do } \\
\text { Programa Bolsa Verde } \\
\text { - Ampliar em } 700.000 \text { toneladas a } \\
\text { capacidade estática de armazenagem da } \\
\text { Companhia Nacional de Abastecimento } \\
\text { - } 13 \text { Planos estaduais de Segurança } \\
\text { Alimentar e Nutricional elaborados. }\end{array}$ \\
\hline Zona Costeira & $\begin{array}{l}\text { Erosão costeira e inundação; } \\
\text { intrusão salina; acidificação } \\
\text { comprometimento dos recursos } \\
\text { naturais e biodiversidade }\end{array}$ & $\begin{array}{l}\text { Estudos para elaborar } \\
\text { a proposta de metodologia para } \\
\text { compatibilizar a altimetria continental } \\
\text { com a batimetrial, além de fazer } \\
\text { um levantamento de custos de } \\
\text { implementação em áreas-piloto do } \\
\text { litoral brasileiro. }\end{array}$ \\
\hline
\end{tabular}

Fonte: Elaborada a partir de informações do Relatório de Monitoramento e Avaliação do Plano Nacional de Adaptação à Mudança do Clima (MMA, 2017)

A análise dos principais riscos identificados no conteúdo do PNA, em cada setor estratégico, face às medidas adotadas para a sua gestão (Tabela 2), permite constatar que a maioria das ações implementadas estão relacionadas com os três setores estabelecidos como prioritários pelo PNA. Dentre as medidas implementadas, destacam-se as de cunho não estrutural, ligadas à ampliação de estudos, disseminação de informação e monitoramento. Considerando-se que houve um período de sete anos entre a criação da Política Nacional, em 2009, e a implementação do PNA, a ausência de estudos em vários setores pode ser vista como uma falha preocupante neste processo. Evidencia-se que a criação de medidas de estratégicas de 
adaptação está diretamente relacionada com os conhecimentos em relação aos riscos (FRÖHLICH e KNIELING, 2013; HILL e DINSDALE, 2003), capazes de determinar o grau de periculosidade que apresentam, a partir da relação probabilidade e consequências (COROMINAS, et. al., 2015; MENDES, 2015).

O relatório reconhece a ausência de conhecimentos específicos sobre os impactos climáticos como um dos grandes desafios (FRÖHLICH e KNIELING, 2013), motivo pelo qual muitos deles não possuem medidas estratégicas previstas, mas sim, previsão de estudos a serem desenvolvidos visando, futuramente, subsidiar a proposição de medidas. Contudo, o relatório indica a ausência de recurso para financiamento de pesquisa em vários setores.

A análise das principais ações estratégicas adotadas no âmbito da PNA (Tabela 2) permite verificar que são várias as lacunas e limitações no processo de identificação e implementação de estratégias de adaptação. Salienta-se o baixo número de medidas aplicadas a nível nacional e estadual, com a concentração de algumas medidas em âmbito municipal, embora a dimensão de escalas não esteja demarcada no PNA e haja poucos municípios atendidos, considerando-se que o país conta com mais de cinco mil municípios. Além disso, nas estratégias implementadas, não se evidencia a interdependência entre os setores, também não se identifica a adoção de políticas coordenadas entre as esferas federal, estaduais e municipais.A ausência da demarcação das escalas no PNA, conforme salientado, é ponto que merece atenção pois, tendo em vista as dimensões continentais do Brasil, a descentralização das ações, de modo planejado e a abarcar as especificidades de cada caso, é ponto fundamental para a eficácia de qualquer política estratégia em âmbito nacional.

O PNA dispõe que a visão que o fundamenta é o de que todos os setores, dentro de quatro anos, possuam estratégias estruturadas para a gestão do risco climático; contudo, apesar de existirem os onze setores estratégicos delimitados no plano, foram eleitos, dentre eles, três setores como sendo prioritários, nomeadamente segurança alimentar e nutricional, recursos hídricos e energética. Esta opção levou a um apagamento dos demais setores, tendo em vista o baixo número de ações empreendidas, a maioria delas direcionadas ao desenvolvimento de estudos na área ou ampliação de pesquisas em andamento.

No relatório do PNA, afirma-se que $100 \%$ das metas e $67 \%$ das diretrizes setoriais tiveram alguma ação correspondente implementada. 
De acordo com o referido documento, entre as ações efetivadas, $72 \%$ contribuem para a identificação e proposição de medidas de adaptação e redução do risco climático (MMA, 2017, p. 10). Ainda que os dados estatísticos projetem um cenário otimista, ao verificar as ações estratégicas empreendidas (Tabela 2), identifica-se que não há efetiva proposição de medidas de adaptação e redução do risco climático, mas sim, a identificação da necessidades de estudos científicos nos diversos setores estratégicos. Ademais, a expressão "com alguma ação implementada" diz muito pouco ou quase nada em termos de análise de eficácia de uma política (PARTIDÁRIO, 2012; HILL e DINSDALE, 2003).

No que tange ao processo participativo,embora o PNA afirme este caráter da política e, mesmo diante de sua abertura para consulta pública quando de sua criação, não se verifica a presença de atores não governamentais, ou da sociedade civil no processo de implementação do plano, integrando-os como sujeitos participantes, tampouco a previsão de instrumentos de participação e monitoramento do PNA, sugerindo que a política não proporciona, efetivamente, a abertura de espaços de diálogo.

Outro ponto relevante do relatório centra-se nos objetos das ações empreendidas (Tabela 2). Verifica-se que nem todas elas referem-se diretamente às mudanças climáticas e, diante da forma como aparecem (isoladas, genéricas, em escalas ora estaduais, ora municipais), infere-se que sejam ações já empreendidas em pastas ministeriais no âmbito de outras políticas já em andamento, mas não decorrentes do PNA, conclusão esta reforçada por comentários presentes no próprio relatório do PNA, entre eles o referente às ações do setor estratégico - 'cidades', em que se afirma que "há conhecimento de ações realizadas, mas não há ainda um levantamento oficial dessas atividades" (MMA, 2017, p. 79).

\subsection{Discussão de resultados - desafios para a governança ambiental}

A estruturação de uma governança ambiental a nível nacional, capaz de gerir os riscos climáticos, depende diretamente do processo de internalização das convenções internacionais e da coerência entre as políticas públicas e os instrumentos decorrentes. Neste sentido, da análise do Plano Nacional de Adaptação à Mudança Climática - PNA, identificase uma série de limitações que podem constituir objeto de preocupação.

Inicialmente, pondera-se que a construção de um plano estratégico depende de estudos prévios, tendo por objetivo identificar os riscos, 
compreender sua complexidade e periculosidade, projetando cenários capazes de subsidiar a criação de medidas adequadas para equacionar as vulnerabilidades e realizar a gestão eficiente dos riscos. (AYALACARCEDO, 2002; TAVARES, 2013). A ausência ou insuficiência de estudos sobre os impactos das alterações climáticas em diversos setores estratégicos, conforme demarcado no Relatório de Monitoramento e Avaliação do PNA (MMA, 2017), contribui diretamente para a ausência de estratégias em vários setores. Além disso, o Relatório indica a ausência de recurso para financiamento de pesquisa em vários setores. Identifica-se, neste contexto, um conflito entre a dimensão estratégica do plano e o seu desenvolvimento, diante de suas limitações, podendo-se afirmar que, em determinados setores, não se tem propriamente um plano de adaptação, visto que se encontram ainda na fase de identificação e análise dos fatores de risco, impactando negativamente na eficácia da política.

Outro ponto de preocupação é a ausência da demarcação de escalas no PNA. A demarcação de escalas tem a finalidade de definir estratégias capazes de abarcar os diferentes contextos (CUNHA et al., 2011; TAVARES, 2013) e, a considerar as dimensões territoriais do Brasil, esta demarcação é crucial para a gestão de riscos, fundamentalmente em escala local (TAVARES, 2013), viabilizando uma melhor avaliação dos riscos, tomadas de decisões, aplicação de medidas de monitorização e a participação dos atores sociais, diante dos diferentes tipos de riscos e complexas realidades do contexto do país (UFSC, 2016), articulando com medidas em escala nacional. A ausênca desta demarcação de escalas no PNA impacta, ainda, na impossibilidade de adoção de soluções mais adequadas relativas à análise de custo-benefício das medidas a serem adotadas (TAVARES, 2013), com melhor alocação de recursos (CUNHA et al., 2011), impactando, também, na identificação da distribuição do risco (BECK, 2011) e, assim, na definição de níveis de intervenção prioritários.

Visando garantir que as preocupações e princípios das alterações climáticas, presentes nas Conveções Internacionais, possam ser assimilados e incorporados nas diversas áreas de política pública de cada país, é próprio do planejamento estratégico eleger setores prioritários de atuação (MATUS, 1996). Neste sentido, o PNA estrutura-se a partir da eleição de onze setores estratégicos, sendo reconhecida no plano a necessidade de coordenação entre eles. Contudo, não se identifica, a partir das medidas implementadas, a transversalidade do plano com a coordenação dos setores estratégicos, valorizando a necessária interdependência dos mesmos, a 
partir da articulação de ações conjuntas. Moura e Bezerra (2016, p. 92) identificam essa tendência nas políticas ambientais brasileiras, em que se vislumbra uma aparente contradição entre os avanços institucionais (arcabouço legal e jurídico) e os problemas ambientais brasileiros, diante "do processo coorporativo e personalista da definição das políticas públicas que levam à setorialização e à falta de coordenação na tomada de decisão sobre a execução de planos e ações de promoção ao desenvolvimento", afetando diretamente a coerência e efetividade da política.

A análise do processo de institucionalização da Política Nacional sobre Mudança do Clima mostra a adoção de um discurso de alinhamento da política com o "fomento do setor produtivo e com as metas nacionais de desenvolvimento socioeconômico e redução das desigualdades regionais". Este aspecto reflete um discurso dinâmico subjacente à narrativa governamental tal como referido em Phillips, et. al. (2004), mas dissociado do social, refletindo a materialidade contraditória do discurso, comumente presente nas políticas públicas brasileiras, conforme identifica Orlandi (2010).

Outro ponto que evidencia uma aparente contradição no PNA é a participação dos diferentes atores sociais. Ao se restringir a participação ao processo de consulta pública do texto do plano, antes de sua implementação, abandona-se uma das importantes dimensões da governança (ARAGÃO, 2008). Infere-se que a ausência de participação pode afetar diretamente a eficácia do PNA, limitando a absorção das várias dimensões que são relevantes à política, (FRÖHLICH e KNIELING, 2013) e necessárias para o processo cíclico (TAVARES, 2013) de monitoramento e avaliação. Compreendendo que a governança envolve, "além das questões políticoinstitucionais de tomada de decisão, as formas de interlocução do Estado com os grupos organizados da sociedade no que se refere ao processo de definição, acompanhamento e implementação de políticas públicas" (MOURA e BEZERRA, 2016, p. 93), evidencia-se que os instrumentos de governança dependem diretamente do caráter democrático dos processos de decisão, com o envolvimento dos novos atores emergentes (BURSZTYN e BURSZTYN, 2012), garantindo uma melhor qualidade das decisões, reforçando a confiança nas instituições públicas e conciliando interesses (KNIELING e LEAL FILHO, 2013), compreendendo que "a ciência e a técnica são apenas realidades parciais no contexto dos processos de decisão sobre os riscos", (MAZZUOLI e AYALA, 2012, p. 317).

A ausência de previsão de ferramentas de avaliação do plano, 
identificando os critérios a serem utilizados neste processo, também constitui um limitador ao envolvimento e participação dos diferentes atores sociais. Ademais, o relatório não deixa clara a fase de implantação de suas metas, apenas indicando, no item "situação", que elas se encontram no estágio "com alguma ação iniciada" ou "sem ação realizada" (MMA, 2017), não sendo possível avaliar o quanto se avançou, ou não, em cada setor, demarcando a falta de transparência na tomada de decisão e execução de planos e ações (ORLANDI, 2010; MOURA e BEZERRA, 2016).

A análise da Política Nacional sobre Mudança do Clima (PNMC) e o seu principal instrumento (Plano Nacional de Adaptação à Mudança Climática - PNA) frente às Convenções sobre Mudança do Clima, mostra, assim, a necessidade de revisão do PNA, tendo em vista metas claras e objetivas (PARTIDÁRIO, 2012), a previsão dos critérios de avaliação e a adoção de ações efetivamente direcionadas para as ameaças das alterações climáticas, a partir da participação dos diferentes setores da sociedade (ARAGÃO, 2008; TAVARES, 2013; BURSZTYN e BURSZTYN, 2012; PORTO e PORTO, 2015), conjugando esforços e conhecimentos, resgatando os objetivos assumidos em âmbito global e garantindo uma governança das mudanças climáticas a nível nacional, capaz de garantir as gerações presentes e futuras (ARAGÃO, 2008).

\section{CONSIDERAÇÕES FINAIS}

Este artigo teve por objetivo identificar e analisar o modo como as Convenções sobre Mudança do Clima vêm sendo internalizadas pela legislação brasileira e incorporadas nas políticas públicas e em que medida estas políticas de adaptação às alterações climáticas se traduzem em instrumentos de gestão de riscos. Os instrumentos internacionais representam a conjugação de interesses comuns de diversos países na persecução de um ambiente equilibrado, assumindo uma agenda que visa equacionar os impactos do crescimento populacional, os avanços do processo produtivo e o potencial lesivo da atividade humana sobre o ambiente, garantindo o acesso aos recursos naturais às gerações presentes e futuras. Nesse sentido, a Convenção-Quadro das Nações Unidas sobre Mudança do Clima representa importante instrumento direcionado à estruturação de uma governança ambiental a nível internacional.

Tendo em vista a implementação da convenção no âmbito nacional, o Brasil criou um robusto arcabouço legislativo dedicado às 
questões ambientais e a gestão dos riscos provenientes das alterações climáticas. Entretanto, há ainda um longo caminho a ser percorrido para efetiva aplicação dessas políticas, tendo em vista, comumente, esbarrarem em decisões que valorizam o aspecto econômico em detrimento do social, ambiental e cultural.Os documentos de política analisados refletem que as estratégias não são vislumbradas de modo integrado, sendo assumidas por diferentes setores governamentais, resultando em agendas ministeriais nem sempre capazes de estabelecer o necessário diálogo. Ademais, as lacunas de conhecimento são um grande desafio para a gestão dos riscos climáticos, pois inviabilizam a proposição de medidas estratégicas de adaptação.

Tendo a gestão participativa como um dos elementos integrantes da governança ambiental e dos riscos, visando ao desenvolvimento da capacidade adaptativa da sociedade, verifica-se que há poucos instrumentos que viabilizam esta participação, em direta oposição aos princípios norteadores da agenda instituída internacionalmente, a partir das convenções, contribuindo para o baixo índice de implementação de várias políticas e consequente dificuldade em cumprir a agenda assumida em âmbito internacional.

A análise do Plano Nacional de Adaptação à Mudança Climática, visando verificar a concretização de seus objetivos e estratégias, contribui para identificar as lacunas e limitações que impactam na coerência e eficácia da Política Nacional sobre Mudança do Clima (PNMC). Neste sentido, indentificou-se a ausência de estudos sobre riscos, a ausência de previsão dos critérios para o processo de avaliação do plano, a falta de coordenação entre os setores estratégicos, a não demarcação de escalas e as limitações do processo participativo, como os principais desafios a serem superados no âmbito do PNA, garantindo seus contributos para a gestão dos riscos, no âmbito do processo de governança ambiental nacional.

Entretanto, a metodologia se mostrou limitada para fornecer uma visão geral da política, considerando que ela é composta de outros instrumentos que não foram analisados neste estudo, motivo pelo qual identifica-se a necessidade de novos estudos, abarcando os demais instrumentos decorrentes da PNMC, viabilizando uma análise de conjuntura, capaz de fornecer elementos suficientes para melhor compreender e avaliar a implementação das convenções internacionais sobre mudanças climáticas no Brasil e, assim, propor contributos mais consistentes para a efetividade da política. 


\section{REFERÊNCIAS}

ARAGÃO, Alexandra. Princípio da precaução: manual de instruções. RevCEDOUA -Revista do Centro de Estudos de Direito do Ordenamento, do Urbanismo e do Ambiente. Faculdade de Direito de Coimbra, v. 2, p. 9-57, 2008.

AYALA-CARCEDO, Francisco Javier. Introducción al análisis y gestión de riesgo. In: AYALA-CARCEDO, Francisco Javier; CANTOS, Jorge Olcina. Riesgo naturales. Barcelona: Ariel Ciencia,2002, p. 133-146.

BECK, Ulrich. Sociedade de risco: rumo a uma outra modernidade. Trad. Sebastião Nascimento. $2^{\mathrm{a}}$ ed. São Paulo: Editora34, 2011.

BURSZTYN, M.; BURSZTYN, M. A.Fundamentos de política e gestão ambiental: os caminhos do desenvolvimento sustentável. - Rio de Janeiro: Garamond, 2012.

CHOU, Sin.Chan.et al. Evaluation of the Eta Simulations Nested in Three Global Climate Models. American Journal of Climate Change, v. 3, p. 438454, 2014.

COMMISSION ON GLOBAL GOVERNANCE. Our global neighborhood: the report of the commission on global governance. London: Oxford University Press, 1995.

COROMINAS, Jordi.et al. Glossary of Terms on Landslide Hazard and Risk. In: G. Lollino et al. (eds.), Engineering Geology for Society and Territory, v 2. 2015, p. $1775 \square 1780$.

CUNHA, Lúcio; MENDES, José Manuel; TAVARES, Alexandre; FREIRIA, Susana. Construção de modelos de avaliação de vulnerabilidade social a riscos naturais e tecnológicos:o desafio das escalas. In: SANTOS, Norberto; CUNHA, Lúcio. Trunfos de uma Geografia Activa: desenvolvimento local, ambiente, ordenamento e tecnologia. Imprensa da Universidade de Coimbra, 2011, p. 627-637.

DINIZ, Eli. Governabilidade, Democracia e Reforma do Estado: Os 
Desafios da Construção de uma Nova Ordem no Brasil dos Anos 90.DADOS

- Revista de Ciências Sociais. Rio de Janeiro, v. 38, n. 3, p. 385-415, 1995.

FIOCRUZ, Vulnerabilidade à mudança do Clima. Disponível em https:// projetovulnerabilidade.fiocruz.br/o-projeto. Acesso em: 15 de jan. 2018.

FRÖHLICH, Jannes. KNIELING, Jorge. Conceptualising Climate Change Governance. In: KNIELING. Jorge; LEAL FILHO, Walter. Climate Change Management. Springer-Verlag Berlin Heidelberg, 2013, p. 9-26.

HENKIN, Louis et al. Human rights. New York: New York Fundation Press, 1999.

HILL, Stephen; DINSDAL, Geoff. Uma base para o desenvolvimento de estratégias de aprendizagem para a gestão de riscos no serviço público. Brasília: Cadernos ENAP 23, 2003.

IPCC. Summary for policymakers. In: Climate Change 2014: Impacts, Adaptation, and Vulnerability. Part A: Global and Sectoral Aspects. Contribution of Working Group II to the Fifth Assessment Report of the Intergovernmental Panel on Climate Change [Field, C.B., V.R. Barros, D.J. Dokken, K.J. Mach, M.D. Mastrandrea, T.E. Bilir, M. Chatterjee, K.L. Ebi, Y.O. Estrada, R.C. Genova, B. Girma, E.S. Kissel, A.N. Levy, S. MacCracken, P.R. Mastrandrea, and L.L.White (eds.)]. Cambridge University Press, Cambridge, United Kingdom and New York, NY, USA, p. 1-32, 2014.

KNIELING. Jorg; LEAL FILHO, Walter. Climate Change Governance. Climate Change Management. Springer-Verlag Berlin Heidelberg, 2013.

MATUS, Carlos. Política, planejamento e governo. Brasília: Ipea, 1996.

MAZZUOLI, Valério de Oliveira.; AYALA, Patryck de Araujo. Cooperação internacional para a preservação do meio ambiente: o direito brasileiro e a Convenção de Aarhus. Revista Direito GV, v8, São Paulo - Jan-Jun, p. 297-328, 2012.

MAZZUOLI, Valério de Oliveira, TEIXEIRA, G. F. M. International 
Environmental Law and the Greening of the American Convention on Human Rights. Anuario Mexicano de Derecho Internacional, v. 13, p. 145 203, 2013.

MAZZUOLLI, Valério de Oliveira.Curso de Direito Internacional Público. 10 ed. Revista dos Tribunais, São Paulo, 2016.

MENDES, José Manuel. Sociologia do Risco: Uma Breve Introdução e Algumas Lições. Coimbra: imprensa da Universidade de Coimbra, 2015.

MMA - MINISTÉRIO DO MEIO AMBIENTE. Plano Nacional de Adaptação à Mudança do Clima - $1^{\circ}$ Relatório de Monitoramento e Avaliação 2016-2017. Brasília: MMA, 2017. Disponível em: http://www. mma.gov.br/images/arquivo/80182/GTTm/RelatorioMonitoramento.pdf. Acesso em 10 de jan. 2018.

MOURA, Adriana Maria Magalhães de. Trajetória da política ambiental federal no Brasil. In: MOURA, Adriana Maria Magalhães de.Governança ambiental no Brasil: instituições, atores e políticas públicas. Brasília: Ipea,2016, p. $13-43$.

MOURA. Alexandrina Sobreira de.; BEZERRA, Maria do Carmo. Governança e sustentabilidade das políticas públicas no Brasil. In: MOURA, Adriana Maria Magalhães de. Governança ambiental no Brasil: instituições, atores e políticas públicas. Brasília: Ipea,2016, p. 91-110.

ORLANDI, Eni Puccinelli (Org). Discurso e politicas públicas urbanas: a fabricação do consenso. Campinas, SP: Editora RG, 2010.

PARTIDÁRIO, Maria do Rosário. Guia de Melhores Práticas para Avaliação Ambiental Estratégica - Orientações Metodológicas para um pensamento estratégico em AAE. Lisboa: Agência Portuguesa do Ambiente e Redes Energéticas Nacionais, 2012.

PHILLIPS, N.; LAWRENCE, T. B.; HARDY, C. Discourse and Institutions. Academy of Management Review, v. 29, n. 4, p. 635-652, 2004.

PORTO, Philippe Seyfart de Souza; PORTO, Marcelo Firpo de Souza. 
Desastres, crise e justiça ambiental: reflexões a partir do contexto brasileiro. O Social em Questão, XVIII(33), p. 153-176, 2015.

RESEK, José Francisco. Direito internacional público: curso elementar. 15 ed., ver., São Paulo: Saraiva, 2017.

TAVARES, Alexandre Oliveira. Referenciais e modelos de governação dos riscos. In:LOURENÇO, Luciano Fernandes; MATEUS, Manuel Alberto. Riscos naturais, antrópicos e mistos. Homenagem ao Professor Doutor Fernando Rebelo. Coimbra: Departamento de Geografia. Faculdade de Letras. Universidade de Coimbra, 2013, p. 63-83.

UFSC, Universidade Federal de Santa Catarina. Centro Universitário de Estudose Pesquisas sobre Desastres.Relatório de danos materiais e prejuizos decorrentes de desastresnaturais no Brasil: 1995 - 2014/ Centro Universitário de Estudos ePesquisas sobre Desastres; Banco Mundial [Organização RafaelSchadeck] - Florianópolis: CEPED UFSC, 230 p, 2016.

UNFCCC. United Nations Climate Change - Global Climate Action. Disponível em: https://www.unfccc.int/climate-action. Acesso em 05/06/18

WOLKMER, Maria de Fátima. S.; FREIBERGER, Nicole. Política Nacional de Recursos Hídricos: Governança da Água e Cidadania Ambiental. Revista Direito Ambiental e Sociedade - v. 2, n. 1, jun./dez., p. 05-40, 2013. Disponível em: http://www.ucs.br/etc/ revistas/index.php/ direitoambiental. Acesso: 05/06/18

WOLKMER, Maria de Fátima. S; SCHEIBE, Luiz Fernando; HENNING, Luciano Augusto. A Política Nacional de Recursos Hídricos: fundamentos e objetivos estratégicos que orientaram a estruturação do Projeto Rede Guarani/Serra Geral.Campo jurídico.v. 1, n. 2, p. 35-56, 2013.

\section{Como citar este artigo (ABNT):}

IOCCA, Luciana Stephani Silva; FIDÉLIS, Teresa. ALTERAÇÕES CLIMÁTICAS, RISCOS E ESTRATÉGIAS DE ADAPTAÇÃO NO CONTEXTO BRASILEIRO. Veredas do Direito, Belo Horizonte, v. 15, n. 33, p. 131-161, set./dez. 2018. Disponível em: <http://www.domhelder. edu.br/revista/index.php/veredas/article/view/1381>. Acesso em: dia mês. ano.

Artigo recebido em: 17/09/2018

Artigo aceito em: 20/11/2018 